\title{
Attitudes toward predictive testing for Alzheimer's disease in a student population
}

\author{
M. Welkenhuysen ${ }^{1}$, G. Evers-Kiebooms ${ }^{1,2}$ and H. Van den Berghe ${ }^{1}$ \\ ${ }^{1}$ Centre for Human Genetics, University Hospital, Herestraat 49, 3000 Leuven, \\ Belgium and ${ }^{2}$ Department of Psychology, University of Leuven, Tiensestraat 102, \\ 3000 Leuven, Belgium
}

Correspondence to: G. Evers-Kiebooms, Centre for Human Genetics, University Hospital, Herestraat 49, B-3000 Leuven, Belgium

\begin{abstract}
Attitudes toward predictive testing for Alzheimer's disease and knowledge about this disease were investigated in a group of medical and psychology students. Overall, knowledge was poor and their own chance of getting Alzheimer's disease was mostly perceived as small. About half the students thought the development of a predictive test for Alzheimer's disease important, while the other half held the opposite view. Considerable variability was also observed in the judgement of the (dis)advantages of such a test. Only a minority of the students would like to have had a predictive test themselves. Important arguments against a predictive test concerned the absence of a treatment for Alzheimer's disease and the emotional burden of a positive test result. Arguments in favour dealt with the ability to make plans for the future and to prepare oneself for the disease. The divergence in attitudes and opinions reflects the complexity of predictive testing for Alzheimer's disease. Stepwise regression revealed that knowledge about Alzheimer's disease and, to a lesser extent, risk perception are significant predictors of attitudes toward predictive testing. However, they only explain a small part of the variance in attitudes. Moreover, why attitudes are less positive when knowledge and perceived susceptibility increase is not clear.
\end{abstract}

Keywords: Alzheimer's disease - Genetic risk - Late onset disorders - Predictive testing - Risk perception

This article originally appeared in Psychiatric Genetics (1997), 7, 121-126.

\section{INTRODUCTION}

As society is ageing, Alzheimer's disease (AD), the predominant cause of senile dementia, is becoming a major medical, social and economic problem (Davis, 1993). At least one in two demented patients suffers from this degenerative disease of the central nervous system (Van Broeckhoven, 1995a). Alzheimer's disease involves continuous progressive impairment of memory, language, orientation and abstract thinking until nearly all cognitive function is lost. A treatment or method of prevention does not exist. Neuropathologic features of $\mathrm{AD}$ include senile plaques and neurofibrillary tangles in the brain, particularly in the hippocampus and the cerebral cortex. The senile plaques are associated with the $\beta$-amyloid-A4 peptide derived from the amyloid precursor protein (Selkoe, 1993). The neurofibrillary tangles consist of paired helical filaments of the microtubuli-associated protein tau, in an abnormally phosphorylated form (Goedert, 1993). Duration of $\mathrm{AD}$, from first symptoms of memory loss until death, is 10 years on average, but can vary between 5 and 20 years (Schellenberg, 1995). The prevalance rate of $\mathrm{AD}$ increases with age: less than $1 \%$ of the population in Europe between 60 and 75 years suffers from AD, compared with more than $10 \%$ of those more than 80 years old (Rocca et al., 1991). Usually, affected patients eventually require assisted living arrangements or nursing home care.

$\mathrm{AD}$ is an aetiologically heterogeneous disease. Observations of a familial clustering of $\mathrm{AD}$ have led to the conceptualization of a 'familial' form of $\mathrm{AD}$ (with at least one affected first degree relative) in contrast to a 'sporadic' form of the disease (Fitch et al. 1988). Population survey studies report that $25-40 \%$ of the $\mathrm{AD}$ cases are familial (Van Broeckhoven, 1995b). However, familial clustering does not necessarily imply a genetic aetiology for $\mathrm{AD}$ in the family concerned, nor does 'sporadic' $\mathrm{AD}$ exclude a genetic cause. Within the same family, different genetic aetiologies are also possible. Aetiologically, the 
age of onset is probably the most relevant correlative variable (Mullan et al., 1994). In most studies, a cut-off age of 65 years is used to discriminate between early-onset or presenile $\mathrm{AD}$ cases (EOAD) and the late-onset $\mathrm{AD}$ cases (LOAD). Among AD patients, the largest group (approximately $45 \%$ ) comprises sporadic LOAD patients, followed by the familial LOAD patients (approximately $30 \%)$, the sporadic EOAD patients $(15 \%)$, and finally the familial EOAD patients (approximately 10\%; Van Broeckhoven, 1995b). Several recent studies (Schellenberg, 1995) have shown that a significant proportion of LOAD is associated with the $\varepsilon 4$ allele of the apolipoprotein $\mathrm{E}$ gene (the $A P O E$ gene) on chromosome 19 , suggesting that the $A P O E-\varepsilon 4$ allele is a risk factor for LOAD. However, other genetic and/or environmental factors may also play a role in the occurrence of familial LOAD. The aetiology of familial EOAD is less complex: it is inherited as an autosomal-dominant trait. Children of affected persons have a 50\% risk of developing EOAD. Linkage analysis studies in EOAD kindreds have identified three genes that, when mutated, cause EOAD: the amyloid precursor protein gene (the $A P P$ gene) on chromosome 21 ; the presenilin-1 gene (the $P S-1$ gene) on chromosome 14; and the presenilin-2 gene (the PS-2 gene) on chromosome 1 (Van Broeckhoven, 1995a). Mutations in the APP gene represent about 5\% of the EOAD families. The $P S-1$ gene is the major gene for EOAD, causing about $70 \%$ of the EOAD cases. Mutations in the PS-2 gene have been found in seven Volga-German families and in one Italian family (Levy-Lahad et al., 1995, Rogaev et al., 1995). They are expected to be minor genetic causes of EOAD. These recent findings make presymptomatic and prenatal genetic testing possible in EOAD families. Considering the rapid advances in molecular genetics, large-scale predictive testing for LOAD might also be technically feasible in the near future. However, apart from the issue of resources required and financial costs, the introduction of predictive testing for $\mathrm{AD}$ into the clinical setting clearly has important ethical and psychosocial consequences (Lennox et al., 1994). Experiences with predictive testing for Huntington's disease (HD), which is also an incurable neurodegenerative disorder with late onset, have demonstrated this point (de Wert, 1992; Decruyenaere et al., 1995).

Given these important demographic and scientific circumstances, it was the aim of this study to evaluate the attitude toward predictive testing for AD as well as knowledge about this disease in a group of students who are likely to have professional contact with $\mathrm{AD}$ patients and/or families in the near future, i.e. medical students and students in clinical psychology. Specific attention was paid to the complex relationship between knowledge, attitudes and other relevant variables.

\section{METHODS}

\section{Subjects}

The sample comprised 167 subjects; 68 of them (40.7\%) in their third or fourth year of psychology. The others were in their fifth year of medical science. The majority of both groups were female $(89.7 \%$ of psychology students and $63.6 \%$ of medical students). Ages ranged from 20 to 25 years for the psychology students (mean 21.6 years, SD 0.96 years) and from 22 to 28 years for the medical students (mean 22.9 years, SD 1.22 years). A proportion of $9.6 \%$ had a relative with $\mathrm{AD}$, mostly a grandmother or grandfather. Each respondent had been confronted with AD in a course on psychopathology (psychology students) or on neurology (medical students).

\section{Questionnaire}

After a lecture in their standard training programme, the students were asked to complete a self-report questionnaire consisting of two parts. The first part is a Dutch translation of the Alzheimer's Disease Knowledge (ADK) Test (Dieckmann et al., 1988), containing 20 multiple choice questions with five alternative responses: the correct response, three distractors and an 'I don't know' alternative. The questions covered the following areas of knowledge: prevalence (items 1 and 2), aetiology (items 3-5), diagnosis (items 6 and 7), symptoms (items 8-10), proposed cures (items 11, 14 and 15), management of problem behaviours and symptoms (items 12, 13, 16-18), public policy affecting reimbursement and the role of supportive services (items 19 and 20). Further details are given in Dieckmann et al. (1988). The number of correct responses to these 20 items was the total score for knowledge. The second part of the questionnaire dealt with the attitude toward predictive testing for AD. First, a multiple choice question assessed the importance attributed to the development of a predictive test for AD: (1) totally unimportant, (2) rather unimportant, (3) rather important and (4) very important. The subjects were invited to explain their answer. The second multiple choice question investigated to what extent the disadvantages of a predictive test for $\mathrm{AD}$ were perceived as bigger than its advantages: (1) the disadvantages are much bigger than the advantages, (2) the disadvantages are somewhat bigger, (3) the advantages are as big as the disadvantages, (4) the advantages are somewhat bigger and (5) the advantages are much bigger than the disadvantages. Next, the subjects were asked if they would like to have a predictive test for $\mathrm{AD}$ themselves, assuming a test existed: (1) no, certainly not, (2) no, probably not, (3) yes, probably and (4) yes, certainly. The answer 'I do not know' was also provided as an alternative response. An additional multiple choice question asked what the subjects perceived as the most appropriate age to have a predictive test for $\mathrm{AD}$ : (1) between 20 and 30 
years, (2) between 30 and 40 years, (3) between 40 and 50 years and (4) between 50 and 60 years. The alternative 'I am always against predictive testing' could also be chosen. The last two questions in the second part of the questionnaire concerned the subjective perception of their own risk of getting $\mathrm{AD}$. A multiple choice question assessed the qualitative evaluation of each student's own chance of developing AD: (1) no chance at all, (2) a very small chance, (3) a small chance, (4) a moderate chance, and (5) a very big chance. An open-ended question subsequently invited the subjects to translate this qualitative evaluation into a figure or a percentage between zero and 100 .

Completion of the questionnaire took about $20 \mathrm{~min}$. Differences in sample size are explained by the absence of a response to some of the questions.

\section{RESULTS}

\section{Attitude toward predictive testing for Alzheimer's disease}

Table I shows that the students' opinions were about equally spread over the 'unimportant' $v s$. the 'important' alternative answers: $51.8 \%$ of the students thought that the development of a predictive test for $\mathrm{AD}$ was rather or totally unimportant; $48.2 \%$ considered the development of such a test as rather or very important. Explanations for their answer on this multiple choice question were given by 151 students. Most explanations (74.2\%) can be classified as arguments against the development of a predictive test for AD. The most important counter-argument (38.4\% of responses) concerned the fact that a treatment for $\mathrm{AD}$ is not available. Secondly, $27.2 \%$ of responses dealt with the expectation that the knowledge of being a carrier for $\mathrm{AD}$ is too stressful and depressing. Other counter-arguments reported by $5 \%$ or less of the students were the inability to predict the age of onset of the disease, the possibility of discrimination by insurance companies and a general decrease in the quality of life of carriers. About one quarter of the explanations given by the students $(25.8 \%)$ can be considered as arguments in favour of developing a predictive test for $\mathrm{AD}$. Most frequently, these arguments dealt with the ability to make plans for the future and to prepare oneself for the disease (15.9\% explanations). Other arguments in favour of a predictive test, expressed by $5 \%$ or

TABLE I. The importance attributed to the development of a predictive test for $A D$

\begin{tabular}{lc}
\hline & $n=164$ \\
\hline Totally unimportant & $14.6 \%$ \\
Rather unimportant & $37.2 \%$ \\
Rather important & $33.6 \%$ \\
Very important & $14.6 \%$ \\
\hline
\end{tabular}

less of the students, included the conviction that certainty of getting the disease is preferable to uncertainty, the right to be informed about their own health status and the desire not to pass the disease on to the next generation.

The answers on the second multiple choice question concerning the preponderance of advantages or disadvantages of a predictive test for $\mathrm{AD}$ are presented in Table II. About one quarter of the students thought that the advantages of a predictive test for $\mathrm{AD}$ were as big as the disadvantages and nearly one third (31.5\%) judged the advantages to be somewhat bigger than the disadvantages. More than $40 \%$ of the sample was situated on the negative side of the scale, indicating that the disadvantages were, to some extent, bigger than the advantages. The relationship between the judgement of (dis)advantages and the importance attributed to the development of a predictive test for $\mathrm{AD}$, is significant (Pearson; $r=0.72, p<0.001$ ). The greater the advantages of the test outweigh the disadvantages, the greater the reason to develop a predictive test for $\mathrm{AD}$.

The question concerning personal intention regarding a predictive test for $\mathrm{AD}$ elicited 'I do not know' answers for $23.4 \%$ of the students. The results for the subgroup of students choosing one of the other response alternatives (Table III) showed that most of the students were negative about having a test for AD themselves with only $21.9 \%$ reporting a positive intention. As expected, the relationship between personal intention regarding a test for $\mathrm{AD}$ and the two other attitude variables is significant: a more positive personal intention corresponds with a higher degree of importance attributed to the development of a predictive test for $\mathrm{AD}$ (Pearson; $r=0.64, p<0.001$ ) and

TABLE II. The extent to which the advantages of a predictive test for $A D$ are judged as bigger or smaller than its disadvantages

\begin{tabular}{lc}
\hline & $n=165$ \\
\hline The disadvantages are much bigger & $23.0 \%$ \\
The disadvantages are somewhat bigger & $19.4 \%$ \\
The advantages are as big as the & $26.1 \%$ \\
$\quad$ disadvantages & $19.4 \%$ \\
The advantages are somewhat bigger & $12.1 \%$ \\
The advantages are much bigger & \\
\hline
\end{tabular}

TABLE III. Personal intentions regarding a predictive test for $A D$

\begin{tabular}{lr}
\hline & $n=128$ \\
\hline No, I would certainly not have a test myself & $32.0 \%$ \\
No, I would probably not have a test myself & $46.1 \%$ \\
Yes, I would probably have a test myself & $15.6 \%$ \\
Yes, I would certainly have a test myself & $6.3 \%$ \\
\hline
\end{tabular}


with a more positive judgement of the advantages of such a test (Pearson; $r=0.62, p<0.001$ ).

For the question regarding the most appropriate age to have a predictive test for $\mathrm{AD}$, the answers of the students who chose the alternative 'I am always against predictive testing' ( $30.5 \%$ of the total sample) were not included in the analysis. Less than one fifth of the remaining sample (18.8\%) thought between 20 and 30 years the most appropriate age to have a test for $\mathrm{AD}, 25.0 \%$ considered between 30 and 40 years as the most appropriate age, between 40 and 50 years was chosen by $19.6 \%$ and, according to $36.6 \%$, the best age is between 50 and 60 years.

\section{Knowledge about Alzheimer's disease}

The total score for knowledge about $\mathrm{AD}$ as measured by the ADK test ranged from 0 to 19 , with a mean of 9.5 (SD 3.17). The proportion of correct answers in the total sample varied between $10.2 \%$ (item 15 ) and $85.0 \%$ (item 9) and the proportion of 'I don't know' answers between $0.6 \%$ (item 9) and $66.5 \%$ (item 11). The proportion of wrong answers also differed considerably (between $8.4 \%$ for item 18 and $60.8 \%$ for item 8 ). Having a relative with $\mathrm{AD}$ was not associated with a significantly higher total knowledge score ( $t$-test). No evidence was found for associations with gender or age.

\section{Subjective perception of the personal risk of getting Alzheimer's disease}

For the qualitative evaluation of each student's own chance of developing $\mathrm{AD}$, the following results were obtained: $1.8 \%$ of the total sample thought they had no chance at all, $28.2 \%$ thought of the chance as very small, $41.1 \%$ considered the chance as small, $27 \%$ thought the chance moderate and $1.8 \%$ considered it very big. The translation of this qualitative evaluation into a figure or percentage between zero and 100, ranged from 1 to 70 , with a mean quantitative risk estimation of 10.5 (SD 12.63). Subsequent correlational analyses (Pearson) showed that the qualitative evaluation was positively related with the quantitative estimation of their own chance $(r=0.51 ; p<0.001)$. These two measures of risk perception are not related to sociodemographic variables, nor being related to an $\mathrm{AD}$ patient, nor the total score for knowledge on the ADK test.
TABLE IV. Pearson correlations of the attitudinal variables with knowledge and subjective risk perception

\begin{tabular}{|c|c|c|}
\hline & $\begin{array}{l}\text { Knowledge } \\
\text { (ADK test) }\end{array}$ & $\begin{array}{l}\text { Qualitative } \\
\text { risk estimation }\end{array}$ \\
\hline \multicolumn{3}{|l|}{ Attitudinal variables } \\
\hline $\begin{array}{l}\text { Importance of developing } \\
\text { a predictive test }\end{array}$ & $-0.37^{\star \star}$ & $-0.20^{\star}$ \\
\hline $\begin{array}{l}\text { Judgement of advantages } \\
\text { Personal intentions }\end{array}$ & $\begin{array}{l}-0.28^{\star \star} \\
-0.43^{\star \star}\end{array}$ & $\begin{array}{l}-0.20^{\star} \\
-0.11 \text { (NS) }\end{array}$ \\
\hline
\end{tabular}

NS, not significant; ${ }^{*} p<0.01 ;{ }^{* *} p<0.001$.

\section{The relationship between attitude, knowledge and risk perception}

Gender, age, being related to an $\mathrm{AD}$ patient and quantitative risk estimation were not significantly correlated with the three attitude variables. The significant Pearson correlations between the attitudinal variables and the variables knowledge and qualitative risk estimation are presented in Table IV. To test to what extent the three attitude variables can be predicted by (a combination of) these six variables a series of stepwise multiple regression analyses was performed. Table $\mathrm{V}$ contains the resulting regression equations. Sixteen percent of the variance in importance attributed to the development of a predictive test for AD and $10 \%$ of the judgement of the (dis)advantages of such a test were accounted for by knowledge and by qualitative risk estimation. The higher the score for knowledge on the $\mathrm{ADK}$ test and the higher the qualitative risk estimation, the less positive the students were toward the development of the test and the less the advantages of such a test were seen as outweighing its disadvantages. As for the third attitude variable, knowledge was the sole predictor: $18 \%$ of the variance in the students' personal intentions regarding a predictive test for $\mathrm{AD}$ was accounted for by their knowledge about $\mathrm{AD}$. The higher their score on the ADK test, the less inclined they were to have a predictive test themselves.

\section{DISCUSSION}

The students' level of knowledge about $\mathrm{AD}$ as measured with the ADK test, was low. Generally, the students could

TABLE V. Regression analyses with the attitudinal variables as response variables

\begin{tabular}{lll}
\hline Response variable & Regression equation & $R^{2}\left(\operatorname{Adj} R^{2}\right) ; p$ \\
\hline Importance & $4.07-0.11$ Knowledge -0.18 Qualitative risk estimation & $0.17(0.16) ; p<0.001$ \\
Advantage & $4.71-0.12$ Knowledge -0.25 Qualitative risk estimation & $0.11(0.10) ; p<0.001$ \\
Intention & $3.73-0.13$ Knowledge & $0.19(0.18) ; p<0.001$ \\
\hline
\end{tabular}

Importance, importance of developing a predictive test for AD; Advantage, judgement of advantages and disadvantages of a predictive test; Intention, personal intention. 
not answer more than half the test items correctly. The mediocrity of their performance was due to a lack of knowledge and misconceptions, which were not confined to a specific area. The fairly high proportion of wrong answers for certain test items suggests that, for some students, admitting that they did not know the answer might have been difficult, and therefore they started guessing the correct answer. Following this line of reasoning, a correct answer might have been the result of a guess, rather than a reflection of knowledge. The possible influence of guessing poses problems on the interpretation of the total score for knowledge. This has to be considered when looking for relationships involving this score for knowledge. The fact that the ADK test contained rather divergent items in equally divergent areas of knowledge (Dieckmann et al., 1988), also complicated the interpretation of the results of analyses involving ADK scores (e.g. the potential predictive value of the total score for knowledge, cf. infra).

Contrary to expectations, the subjects who had a relative with $\mathrm{AD}$ did not perform any better on the ADK test than the others. However, a significant effect on knowledge was difficult to obtain, given the small number of students with an $\mathrm{AD}$ patient in their family. The latter can also explain the absence of an effect on the subjective perception of each student's own risk of developing AD: the small subgroup of $\mathrm{AD}$ relatives reported the same low level of personal susceptibility as the group of 'non $\mathrm{AD}$ relatives'. However, in this respect, the students' lack of knowledge about the complex aetiology of the disease and its prevalence probably played a major part as well.

Regarding the attitude toward predictive testing for $\mathrm{AD}$, a lot of variability was observed in the degree of importance attributed to the development of a predictive test for $\mathrm{AD}$ : about half the students considered the development of a predictive test as rather or totally unimportant, while the other half considered this as rather or very important. Considerable difference also existed in the extent to which the advantages were judged as bigger or smaller than the disadvantages, with a relatively large proportion of students (more than $40 \%$ ) expressing a negative attitude. Much variability also existed in their choice of the most appropriate age interval for having a test for $\mathrm{AD}$ (about $30 \%$ of the total sample did not choose an interval). Less difference was observed in the personal intention of having a predictive test for $\mathrm{AD}$ : nearly $80 \%$ of the subgroup reporting a personal intention (76.6\% of the total sample), would not have a predictive test.

Only a relatively small part of the variance in the attitudinal variables is accounted for by the other variables in this study. Stepwise regression analyses have shown that the total score for knowledge about AD on the ADK test is the best predictor for all three attitudinal variables. The qualitative estimation of the personal risk of getting AD has additional predictive value when the importance of developing a predictive test and the judgement of the (dis)advantages are considered. When the level of knowledge about $\mathrm{AD}$ increases, the attitude toward predictive testing for $\mathrm{AD}$ becomes more negative. However, the nature of the ADK test (cf. supra) complicates the interpretation of these findings. The negative relationship between the qualitative evaluation of risk, on the one hand, and the importance attributed to the development of a predictive test for $\mathrm{AD}$, on the other, as well as the judgement of the advantages of such a test, is difficult to explain, especially because of the absence of a relationship with personal intention regarding a predictive test.

The small proportion having a positive personal intention in our study contrasts with the majority having a positive intention (64\%) obtained in a group of individuals at $50 \%$ risk for $\mathrm{EAD}$ and/or cerebral haemorrhagia or at $50 \%$ risk for hereditary Pick disease, another autosomal dominant neurodegenerative disease (Tibben et al., 1997). This difference might be due to the difference in the size of the risk and in personal experience of the disease. Compared with studies of HD a similar discrepancy exists: $66 \%$ of a group at risk for this autosomal dominant disease (EversKiebooms, 1990) but also 53\% of a group of young women without an increased risk (Decruyenaere et al., 1993) reported a positive personal intention regarding a predictive test for HD. The less positive intentions for AD can be explained, as some subjects in our study did, partly by the more advanced age of onset of $\mathrm{AD}$ and its higher variability. This complicates planning for the future, which is reported as an important argument in favour of a predictive test (Decruyenaere et al., 1993; Tibben et al., 1997). However, as Lennox et al. (1994) have pointed out, another important difference exists. One of the purposes of HD predictive testing programmes has been to offer useful information for reproductive decision making. In contrast, the usually later onset of $\mathrm{AD}$ makes predictive testing less relevant for reproductive decisions. Indeed, family planning or children was mentioned by only a few students.

The minority of subjects having positive personal intention contrasts with the fact that half the students considered the development of a predictive test for $\mathrm{AD}$ as rather or very important. This contrast underlines the significance of the right to know as well as the right not to know: the fact that a genetic test is available does not imply that everybody at risk has to take the test, nor that this test is beneficial for each individual at risk (Wexler, 1992). The large proportion of negative personal intentions in our sample is most often motivated by the absence of a treatment for $\mathrm{AD}$. In a population at risk for $\mathrm{HD}$ (Quaid and Morris, 1993; Decruyenaere et al., 1995) and 
in a group of young women (Decruyenaere et al., 1993) the lack of a treatment was also the major reason for not requesting a predictive test for $\mathrm{HD}$. Similar to the HD studies and to Tibben's research (Tibben et al., 1997), the expectation of the devastating psychological impact of a positive test result is another major drawback.

The low level of knowledge and the divergence in attitudes and opinions reflect the complexity and the problems involved in predictive testing for $\mathrm{AD}$. The issue of ethical, social and psychological consequences of testing for $\mathrm{AD}$ has been raised by several authors (Godard et al., 1994; Karlinsky et al., 1994; Lennox et al., 1994; Post, 1994; Mayeux and Schupf, 1995) and some of these consequences clearly worry the students. Nevertheless, if the limitations of a possible test are carefully explained, and if pre-test and post-test counselling permits an individual to explore fully the personal meaning of a positive or negative test result, it seems reasonable that the decision to undertake predictive testing for $\mathrm{AD}$ should remain the sole choice of the individual concerned.

\section{Acknowlegement}

We greatly acknowledge the contribution of Sarah Trauwaert in conducting the research in partial fulfilment of her licence degree at the University of Leuven.

\section{REFERENCES}

Davis KL (1993) Neuroscience and socioeconomic challenge of Alzheimer's disease. Neurology, 43, (suppl 4), S5.

Decruyenaere M, Evers-Kiebooms $G$ and Van den Berghe $H$ (1993) Perception of predictive testing for Huntington's disease by young women: preferring uncertainty to certainty? Journal of Medical Genetics, 30, 557-561.

Decruyenaere M, Evers-Kiebooms G, Boogaerts A, Cassiman J-J, Cloostermans T, Demyttenaere K, Dom R, Fryns J-P and Van den Berghe H (1995) Predictive testing for Huntington's disease: risk perception, reasons for testing and psychological profile of test applicants. Genetic Counseling, 6, 1-13.

de Wert G (1992) Predictive testing for Huntington disease and the right not to know. Some ethical reflections. Birth Defects: Original Articles Series, 28, 133-138.

Dieckmann L, Zarit SH, Zarit JM and Gatz M (1988) The Alzheimer's disease knowledge test. The Gerontologist, 28, 402-407.

Evers-Kiebooms G (1990) Predictive testing for Huntington's disease in Belgium. Journal of Obstetrics and Gynaecology, 11, 61-72.

Fitch N, Becker R and Heller A (1988) The inheritance of Alzheimer's disease: a new interpretation. Annals of Neurology, 23, 14-19.

Godard B, Knoppers BM, Glass K, Grenon M, Bouchard R, Bouvier M, Goulet J and Gavreau D (1994) Ethical issues involved in establishing a registry for familial Alzheimer's disease. Alzheimer Disease and Associated Disorders, 8, 79-93.
Goedert M (1993) Tau protein and the neurofibrillary pathology of Alzheimer's disease. Trends in Neurosciences, 16, 460-465.

Karlinsky H, Sadovnick AD, Burgess M, Langlois S, Hayden MR and Berg JM (1994) Issues in molecular genetic testing of individuals with suspected early-onset familial Alzheimer's disease. Alzheimer Disease and Associated Disorders, 8, 116-125.

Lennox A, Karlynski H, Meschino W, Buchanan JA, Percy ME and Berg JM (1994) Molecular genetic predictive testing for Alzheimer's disease: Deliberations and preliminary recommendations. Alzheimer Disease and Associated Disorders, 8, 126-147.

Levy-Lahad E, Wasco W, Poorkaj P, Romano DM, Oshima J, Pettingell WH, Yu C, Jondro PD, Schmidt SD, Wang K et al., (1995) Candidate gene for the chromosome 1 familial Alzheimer's disease locus. Science, 269, 973-974.

Mayeux R and Schupf N (1995) Apolipoprotein E and Alzheimer's disease: The implications of progress in molecular medicine. American Journal of Public Health, 85, $1280-1284$

Mullan M, Crawford F and Buchanan J (1994) Technical feasibility of genetic testing for Alzheimer's disease. Alzheimer Disease and Associated Disorders, 8, 102-115.

Post SG (1994) Genetics, ethics, and Alzheimer disease. Journal of the American Geriatric Society, 42, 782-786.

Quaid KA and Morris M (1993) Reluctance to undergo predictive testing: the case of Huntington disease. American Journal of Medical Genetics, 45, 41-45.

Rocca WA, Hofman A, Brayne C, Breteler MMB, Clarke M, Copeland JRM, Dartigues J-F, Engedal K, Hagnell O, Heeren TJ et al., (1991) Frequency and distribution of Alzheimer's disease in Europe: a collaborative study of 1980-1990 prevalence findings. The EURODEMPrevalence Research Group. Annals of Neurology, 30, 381-390.

Rogaev EI, Sherrington R, Rogaeva EA, Levesque G, Ikeda M, Liang Y, Chi H, Lin C, Holman K, Tsuda T et al., (1995) Familial Alzheimer's disease in kindreds with missense mutations in a gene on chromosome 1 related to the Alzheimer's disease type 3 gene. Nature, 376, 775-778.

Schellenberg GD (1995) Genetic dissection of Alzheimer disease, a heterogeneous disorder. Proceedings of the National Academy of Sciences of the USA. 92, 8552-8559.

Selkoe DJ (1993) Physiological production of the $\beta$-amyloid protein and the mechanism of Alzheimer's disease. Trends in Neurosciences, 16, 403-408.

Tibben A, Stevens M, de Wert GMWR, Niermeijer MF, van Duijn CM and van Swieten JC (1997) Preparing for presymptomatic DNA-testing for early onset Alzheimer disease/cerebral haemorrhage and hereditary Pick disease. Journal of Medical Genetics, 34, 63-72.

Van Broeckhoven C (1995a) Presenilins and Alzheimer disease. Nature Genetics, 11, 230-232.

Van Broeckhoven C (1995b) Molecular genetics of Alzheimer disease: Identification of genes and gene mutations. European Neurology, 35, 8-19.

Wexler NS (1992) The Tiresias complex: Huntington's disease as a paradigm of testing for late-onset disorders. The FASEB Journal, 6, 2820-2825.

(Received 30 September 1996; accepted 10 June 1997) 


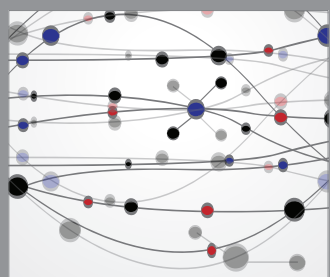

The Scientific World Journal
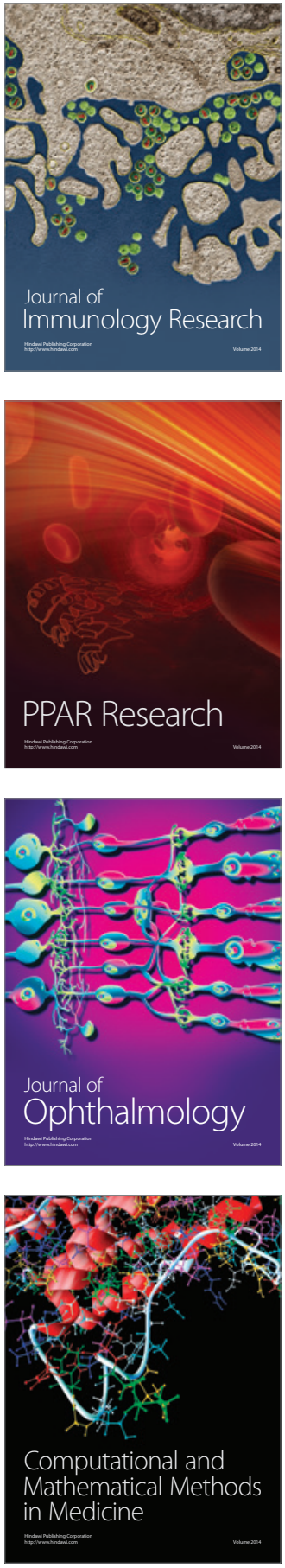

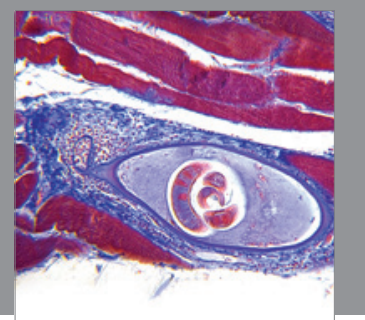

Gastroenterology

Research and Practice
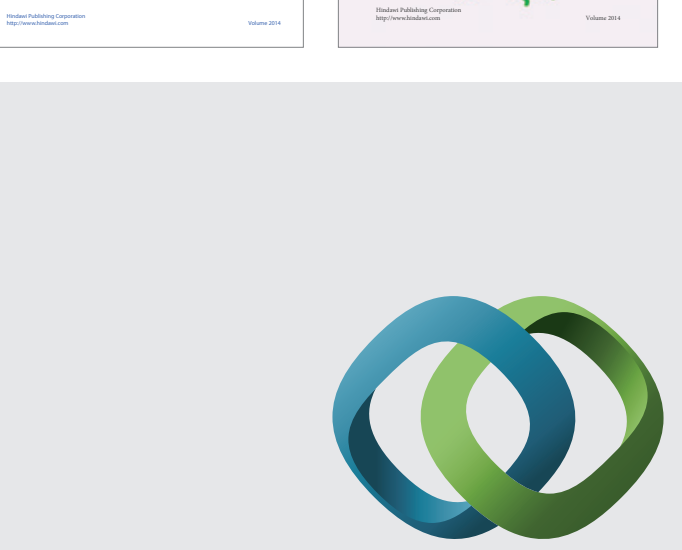

\section{Hindawi}

Submit your manuscripts at

http://www.hindawi.com
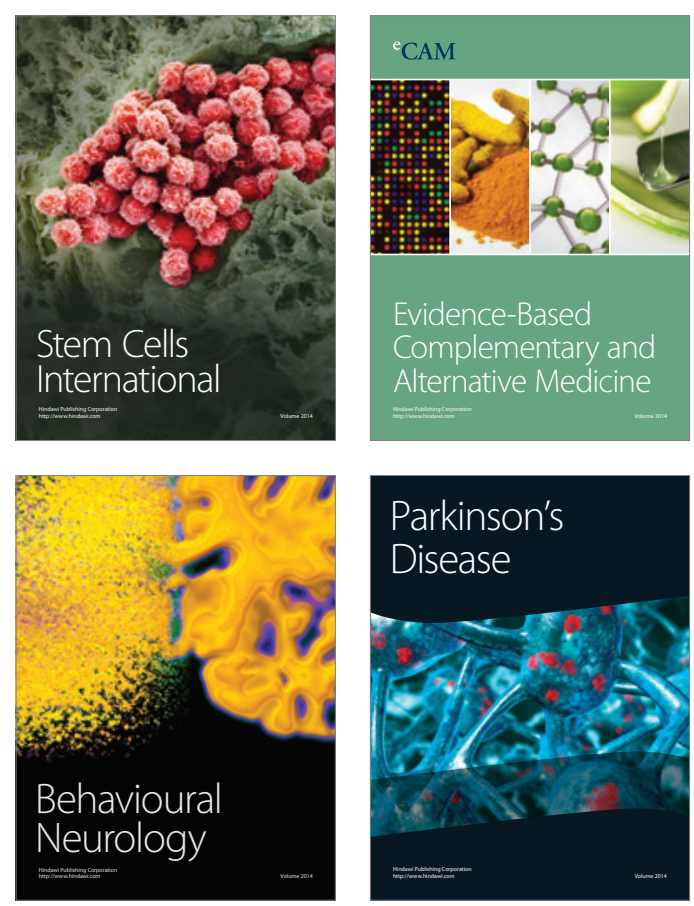

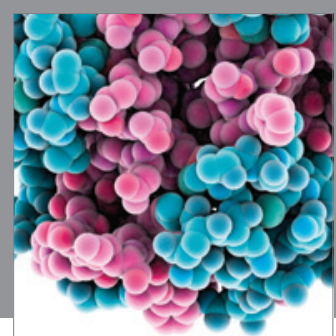

Journal of
Diabetes Research

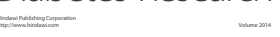

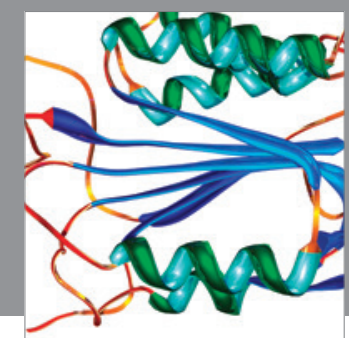

Disease Markers
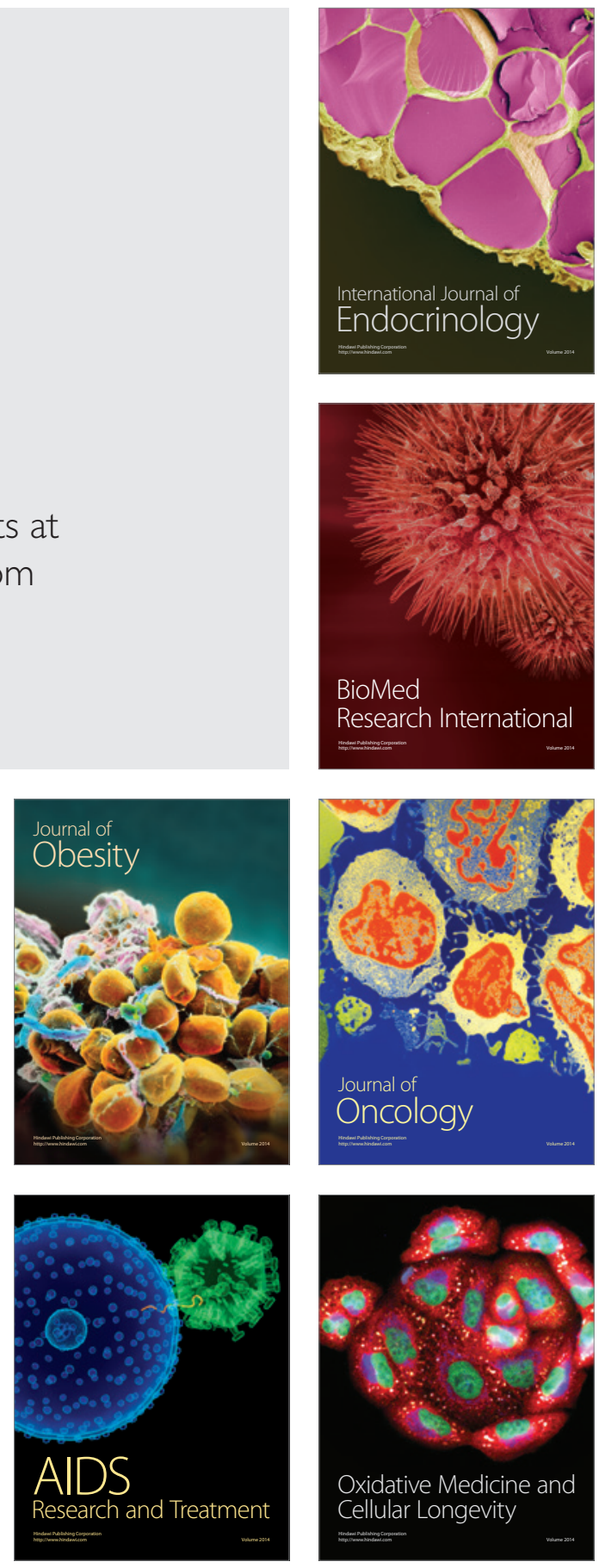